\title{
Modeling and Development of a Novel Quality of Service Prediction Model for Global System for Mobile Communications Network using Artificial Neural Networks
}

\author{
Jide Julius Popoola* and Adewale Enoch A reo \\ Department of Electrical and Electronics Engineering, School of Engineering and \\ Engineering Technology, Federal University of Technology, Akure, Nigeria
}

\begin{abstract}
Quality of service $(Q o S)$ performance evaluation is an essential indicator in determining the efficiency of services rendered by an industry. Comparison of some key performance indicators with standard threshold values has been a major approach for determining QoS of Global System for Mobile Communication (GSM) in Nigeria. This comparative approach, which usually involves human involvement is prone to error. Thus, an automatic artificial neural network (ANN) predictive QoS model was developed in this study and presented in this paper. In carrying out the study, five key performance indicators (KPIS) data were collected from the GSM operator used. The collected KPIs parameters were used to develop a mathematical model that was transformed into the proposed automatic QoS predicted model using ANN. The developed QoS prediction model, when evaluated was found to be accurate and could perform favorably well when compared with the manual approach being used by the Nigerian Communications Commission. The developed automatic QoS prediction model for this study is thus suggested as a better replacement for the current manual method based on its accuracy and non-human involvement in predicting QoS of GSM network being investigated.
\end{abstract}

Keywords: Global System for Mobile Communication, Quality of Service, Customer Satisfaction, Key Performance Indicators.

\section{Introduction}

The global system for mobile communication (GSM) is a worldwide accepted standard for digital cellular communication. It is currently one of the accepted systems used for mobile telecommunications in all parts of world. It is a second generation digital cellular network developed to replace the first generation, which was analogue network. It operates on three different carrier frequencies namely; the $900 \mathrm{MHz}$ band, $1800 \mathrm{MHz}$ band and $1900 \mathrm{MHz}$ band, which is used mainly in the United States. As a cellular network, GSM employs cells to offer wireless communication to subscribers in the vicinity of the cells. The four primary cells, which make up a GSM network, are called macro, micro, pico and femto. While the macro and micro cells provide outdoor coverage, the pico and femto cells are responsible for the indoor coverage.

Basically, GSM can be pictured as a revolutionized technology that indeed transformed the world. This is because it has helped in providing better internet and service connectivity for a series of mobile devices. Without any doubt, a lot of scientific and industrial innovations nowadays would have been infeasible without the introduction of GSM. In Nigeria for instance, introduction of GSM has

\footnotetext{
* Corresponding author. Tel.: +234-803-4131860

E-mail address: jidejulius2001@ gmail.com

Manuscript History:

Received 1 July, 2020, Revised 9 July, 2020, Accepted 12 August, 2020, Published 30 October, 2020
} 
made access to a wide range of wireless services and applications that were not available with government-owned Telecommunication Company called Nigerian Telecommunications Limited (NITEL) accessible to all Nigerians. In addition, the introduction of GSM in Nigeria has made ownerships of phones available to all and sundry, which was never possible with the state-owned or government-owned NITEL. According to [1], before the introduction of GSM in Nigeria, telephone was a luxury that only the few privileged were enjoying. The authors observed that with introduction of GSM in Nigeria about two decades ago, telecommunication in Nigeria has witnessed a tremendous growth. For instance, the data on total number of GSM subscribers provided by the Nigeria Communications Commission (NCC), the body responsible for regulating the operation of telecommunications industries in Nigeria, show that as at October 2019 there were just 180,118,345 GSM subscribers. However, by November 2019 and December 2019, the total number of GSM subscribers had jumped to $182,435,340$ and 184,426,187 respectively, representing an increase of over two million subscribers on a monthly basis. Similarly, the graphical illustration of both data service subscribers and active lines presented in [2], from December 2012 to December 2017 shows an increase of about 7 million and 4 million respectively for data service subscribers and active lines in the country. This rapid increase in subscription level of GSM in Nigeria is stemmed from the positive transformation it has brought to how people learn, live, play and work.

Similarly, in term of economic advantage, the advent of GSM in Nigeria has contributed immensely to the socio-economic growth of the country. For example, the advent of GSM in Nigeria has created investments and employment opportunities in the country. As reported in [3], the advent of GSM in Nigeria had created both direct and indirect jobs for over 1 million Nigerians before 2008. It was reported in [4] that over 2,000 Nigerians were directly employed by GSM companies in Nigeria while an estimated 40,000 persons were benefiting from indirect employment provided by GSM industries in Nigeria. The fact that the advent of GSM in Nigeria had reduced unemployment in Nigeria drastically was also buttressed in [5]. Furthermore, these authors mentioned that GSM has improved the social lives of Nigerians tremendously by encouraging fast information dissemination among people. More so, the advent of GSM in Nigeria has contributed to the nation's economy in diverse ways. For instance, it was reported in [6] that telecommunication sector, which consists of mainly GSM, contributed about 400 billion naira as taxes in 2012 to the Nigeria economy. These authors reported that GSM contributed $0.62 \%$ to $8.53 \%$ to the national gross domestic product (GDP) from 2001 to 2013. Likewise, it was reported in [7] that GSM industry contributed 53\% in 2003 to the nation's GDP and about 2 billion naira, which is equivalent to $8.8 \%$, to the nation's GDP in 2015 .

Although the advent of GSM has brought huge revenue to Nigerians, GSM's operators and the Nigerian government through employment, profit and taxes as well as license fees respectively, quality of service (QoS) remains one principal problem assailing GSM operations in Nigeria. This problem has indeed hindered customer satisfaction, which as reported in [8] is one of the criteria for having sustainable edge in competitive market. This is because QoS is a major parameter normally used in assessing customer satisfaction because it is the index for measuring the capability of cellular service providers to offer a satisfactory service. This makes QoS estimation and categorization a chief activity in present-day GSM networks in Nigeria and other parts of the world. Basically, network service providers or operators are always interested in their network QoS evaluations because a network that offers better QoS compared with other networks will have the assurance of retaining old customers as well as attracting new customers for a longer period of time. Thus, it is imperative for cellular network providers to frequently evaluate their services' qualities and therefore solve possible challenges as well as to deal with the complaints or grievances of the customers [8].

In evaluating QoS of GSM operators in Nigeria, standard or threshold values of some key performance indicators (KPIs) are adopted by the NCC. The values are standalone dedicated control channel congestion rate (SDCCH Cong. Rate), which should be less than or equal to $0.2(\leq 0.2)$ percent, traffic channel congestion rate (TCH Cong. Rate), which should be less than or equal to 2 ( $\leq$ 2) percent, call setup success rate (CSSR), which should be greater than or equal to 98 ( $\geq 98$ ) percent,

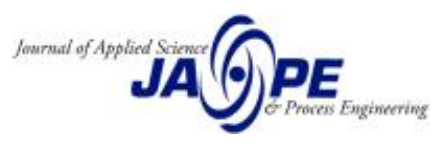


call drop call rate $(\mathrm{CDR})$, which should be less than or equal to $1(\leq 1)$ percent, call completion rate (CCR), which should be greater than or equal to $96(\geq 96)$ percent and handover success rate (HoSR), which should be greater than or equal to $98(\geq 98)$ percent. These KPIs and threshold values are parameters that are usually considered when the network monitoring process is being carried out. The definitions and mathematical expressions of the commonly used KPIs for predicting and evaluating QoS of GSM in Nigeria as well as the set threshold values for these KPIs by NCC in the surveyed literature are presented in Table 1.

Table 1. GSM KPIs definitions with NCC set thresholds (Source: [8])

\begin{tabular}{|c|c|c|c|c|c|c|}
\hline $\begin{array}{r}\mathbf{S} / \mathbf{N} \\
1 .\end{array}$ & \multirow{2}{*}{$\begin{array}{l}\begin{array}{l}\text { Key Performance } \\
\text { Indicator }\end{array} \\
\begin{array}{l}\text { Call Setup Success } \\
\text { Rate }\end{array} \\
\end{array}$} & \multicolumn{2}{|c|}{ Acronym } & Definitions & \multicolumn{2}{|c|}{ Target $(\%)$} \\
\hline 1. & & \multicolumn{2}{|c|}{ CSSR } & $\begin{array}{l}\text { Is the number of the } \\
\text { unblocked call attempts } \\
\text { divided by the total } \\
\text { number of call attempts or } \\
\text { (1 - Blocking Probability) } \\
\text { x } 100 \%\end{array}$ & \multicolumn{2}{|c|}{$\geq 98 \%$} \\
\hline & \multicolumn{6}{|c|}{$\begin{array}{l}\text { According to [1] CSSR is defined mathematically as; } \\
\text { CSSR }=\frac{\text { Number of unblocked call attempts }}{\text { Total numberof call attempts }}=(1-\text { Blocking probability }) \times 100 \%\end{array}$} \\
\hline \multirow[t]{2}{*}{2.} & \multicolumn{2}{|c|}{$\begin{array}{l}\text { Traffic Channel Congestion } \\
\text { \{with Handover (WHO) } \\
\text { and without Handover } \\
(\mathrm{WOH})\}\end{array}$} & TCHCon & \multicolumn{2}{|c|}{$\begin{array}{l}\text { Is the ratio of the number } \\
\text { of unsuccessful TCH } \\
\text { requests to the total } \\
\text { number of TCH request } \\
\text { attempts expressed as } \\
\text { percentage }\end{array}$} & $\begin{array}{l}\leq 2 \% \\
\mathrm{WOH} \\
\leq 4 \% \\
\mathrm{WHO}\end{array}$ \\
\hline & \multicolumn{6}{|c|}{$\begin{array}{l}\text { TCHCon is defined mathematically in }[9] \text { as; } \\
\text { TCHCon }=\frac{\text { Number of calls blocked dueto unavailabk resources }}{\text { Total numberof requests }} \times 100 \%\end{array}$} \\
\hline \multirow[t]{2}{*}{3.} & \multicolumn{2}{|l|}{ Call Completion Rate } & CCR & \multicolumn{2}{|c|}{$\begin{array}{l}\text { Is the ratio of } \\
\text { successfully completed } \\
\text { calls to the total number } \\
\text { of attempted calls }\end{array}$} & $\geq 96 \%$ \\
\hline & \multicolumn{6}{|c|}{ CCR is defined mathematically in [1] as; CCR $=\frac{\text { Total numberof completed call }}{\text { Total numberof call attempts }}$} \\
\hline 4. & Call Drop Rate & & $\mathrm{CDR}$ & $\begin{array}{l}\text { Is the number of dro } \\
\text { calls divided by the } \\
\text { number of call attem }\end{array}$ & & $\leq 2 \%$ \\
\hline
\end{tabular}




\begin{tabular}{|c|c|c|c|c|}
\hline & & & $\begin{array}{l}\text { or (1 - Call Completion } \\
\text { Ratio) x } 100 \%\end{array}$ & \\
\hline & $\begin{array}{l}\text { CDR is defined mathem } \\
C D R=\frac{\text { Numberof }}{\text { Total number }}\end{array}$ & $\begin{array}{l}\text { in [1] as; } \\
\text { lcall } \\
\text { ttempts }\end{array}$ & -Call complete probability)× & $\%$ \\
\hline 5. & $\begin{array}{l}\text { Standalone Dedicated } \\
\text { Control Channel }\end{array}$ & SDCCH & $\begin{array}{l}\text { Is a logical signaling } \\
\text { channel that is used for } \\
\text { call set-up. Once a cell is } \\
\text { successfully setup } \\
\text { SDCCH is released and } \\
\text { RTCH is assigned for the } \\
\text { conversation. }\end{array}$ & \\
\hline & $\begin{array}{l}\text { According to [9] SDCC } \\
\text { SDCCH Congestionr }\end{array}$ & $\begin{array}{r}1-C \\
\text { estion rat } \\
\text { Assi }\end{array}$ & $\begin{array}{l}\text { defined mathematically as; } \\
\frac{R}{\text { nentrate }} \times 100 \%\end{array}$ & (5) \\
\hline 6. & Handover Success Rate & HoSR & $\begin{array}{l}\text { Is the ratio of successfully } \\
\text { handover calls to the total } \\
\text { number of attempted handover } \\
\text { calls }\end{array}$ & $\geq 96 \%$ \\
\hline & $\begin{array}{l}\text { According to [9] HoSR } \\
H o S R=\frac{\text { Number of su }}{\text { Total nun }}\end{array}$ & $\begin{array}{l}\text { d mathe } \\
\text { lycomple } \\
\text { nitiated }\end{array}$ & $\begin{array}{l}\text { ically as; } \\
\text { lhandovers } \\
\text { dovers }\end{array}$ & (6) \\
\hline
\end{tabular}

In Nigeria, many researchers across the country have worked on QoS of GSM networks. Majority of these studies, as reported in [8], made use of four major methods in evaluating QoS parameters relating to voice services offered in cellular mobile networks. The methods, as reported in $[2,8]$, are crowdsourcing, questionnaire, drive test and network management system (NMS). In most of the related studies, [1-2, 8, 10-14], some KPIs indices listed above were computed and compared with standard or threshold values set by NCC. In [1], questionnaire method was employed to investigate QoS of GSM providers in Abuja, the country Federal Capital Territory (FCT) and some selected cities in all the six geo-political zones of the country. The study was conducted for four months (May 2006 - August 2006) using the then four major GSM operators: MTN, Glocom, Celtel and M-Tel. On the other hand, $[2,8,9,12]$, employed drive test method to investigate QoS of current GSM operators in Nigeria. While the studies presented in $[2,8]$ were conducted in Ibadan and Akure in South-West geo-political zone of the country, the study reported in [9] was conducted in Kano city in North-West geo-political zone of the country. Similarly, the study reported in [12] was conducted in Minna the capital of Niger State in North-Central geo-political zone of the country. Findings from almost all these surveyed literature show that the QoS of all the major GSM operators (MTN, Glo, Airtel and 9mobile) in Nigeria was unsatisfactory.

Unfortunately, for almost two decades Nigerians had been complaining on unsatisfactory performances of these GSM operators in Nigeria, it is surprising that the NCC does not have a unique model to automatically evaluate and predict the QoS of mobile operators in the country. In order to 
solve this problem, the study presented in this paper was embarked upon with the aim of developing an automatic artificial neural network (ANN) prediction model that can holistically assess, evaluate, predict and characterize the QoS of mobile network operators on a single platform without human involvement. ANN was employed because of its demonstrated potential in modern decision making processes and object classification [15]. ANN is a non-linear computational algorithm inspired by the structure and learning potential of the human brain. It was employed in this study because it is an acclaimed statistical approach created to develop prediction models [16]. Detailed information on the activities involved in developing the ANN prediction QoS model, using information in Table 1, is presented in the next section. For logical presentation of the study presented in this paper, the organisation of the paper is as follow:. Section 2 presents detailed information on activities involved in carrying out the study. The results obtained from the developed ANN prediction QoS model when evaluated are reported and discussed in Section 3. Finally, Section 4 is the conclusion section with summary of findings from the study.

\section{Methodology}

In carrying out the study reported in this paper, the activities involved were divided into four stages: data acquisition, data normalization, model development and model evaluation. While detailed information on the first three stages (data acquisition, data normalization and model development) is presented in this section, detailed information on the fourth stage (model evaluation) is presented in next section under results and discussion. Activities involved in the first three stages are presented in the following sub-sections: data acquisition, data normalization, and model development.

\subsection{Data acquisition}

Data employed in this study were collected from one of the four major GSM operators in Ekiti State, South-West geo-political zone, Nigeria. The state is located between latitude $7.667^{\circ} \mathrm{N}$ and longitude $5.250^{\circ} \mathrm{E}$ with the capital at Ado-Ekiti. The State as shown in Figure 1 is bounded in the north by both Kogi and Kwara States and shares boundary with Osun State in the west. It has boundary with Ondo State in the south and east. In carrying out the study, five monthly KPIs data from one hundred base-stations or sites of the investigated GSM operators in the State were collected for twelve months (January-December 2017). The data were collected from the counter database of the investigated GSM operator base station controllers across the State. Data on five out of the six KPIs defined in Table 1 were collected namely: SDCCH Cong. Rate, TCH Cong. Rate, CSSR, CDR and HoSR. The summary of the collected data are presented in Figure 2 and Figure 3 using Microsoft Excel Spreadsheet. The summarized data were normalized before they were used as input into the developed QoS prediction model for this study. The procedural details involved in the data normalization are presented in the next subsection. 


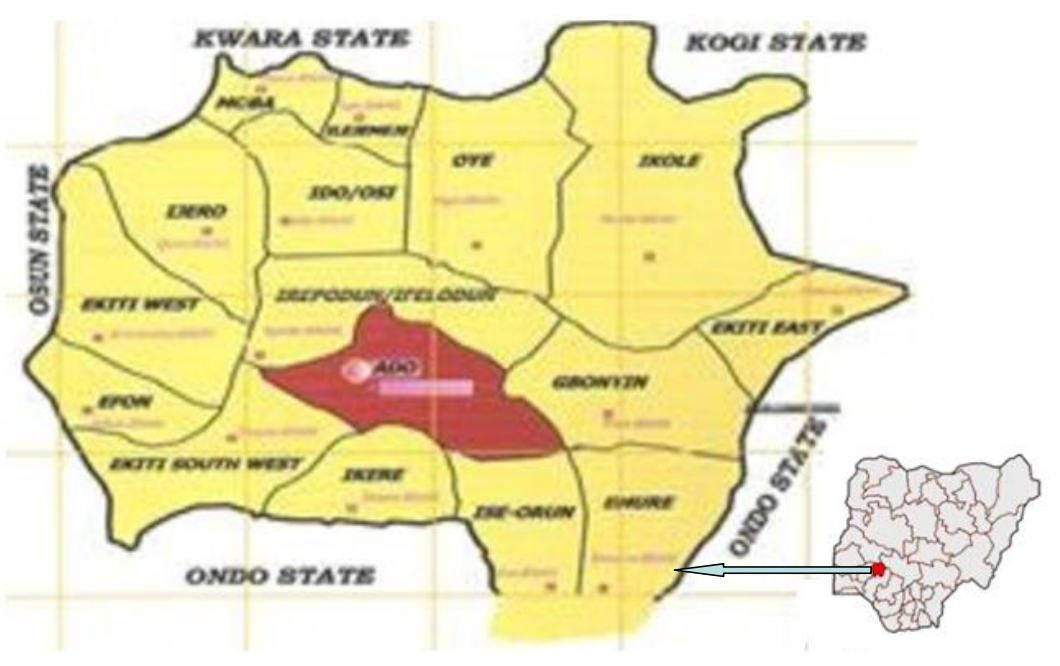

Figure 1. Map of Ekiti State, Nigeria.

\subsection{Data normalization}

Critical observation of the collected KPIs data, as shown in Figure 2 and Figure 3, shows that there are wide disparities among the data. The disparities are a result of the assigned threshold values of $\leq 0.2, \leq 2, \geq 98, \leq 1$ and $\geq 98$ respectively on SDCCH Cong. Rate, TCH Cong. Rate, CSSR, CDR and HoSR. Thus, the five collected KPIs values were normalized using the mathematical expression;

$$
\text { Normalized value }=\frac{x-x_{\min }}{x_{\max }-x_{\min }}
$$

where $x$ is the actual each collected KPI value, $x_{\min }$ is minimum value of each collected KPI and $x_{\max }$ is maximum value of each collected KPI. The obtained normalized data for each of the KPIs values were later used as the input for the development of the desired QoS prediction model for this study. Detailed information on the development of the desired QoS prediction model is given in the next subsection.

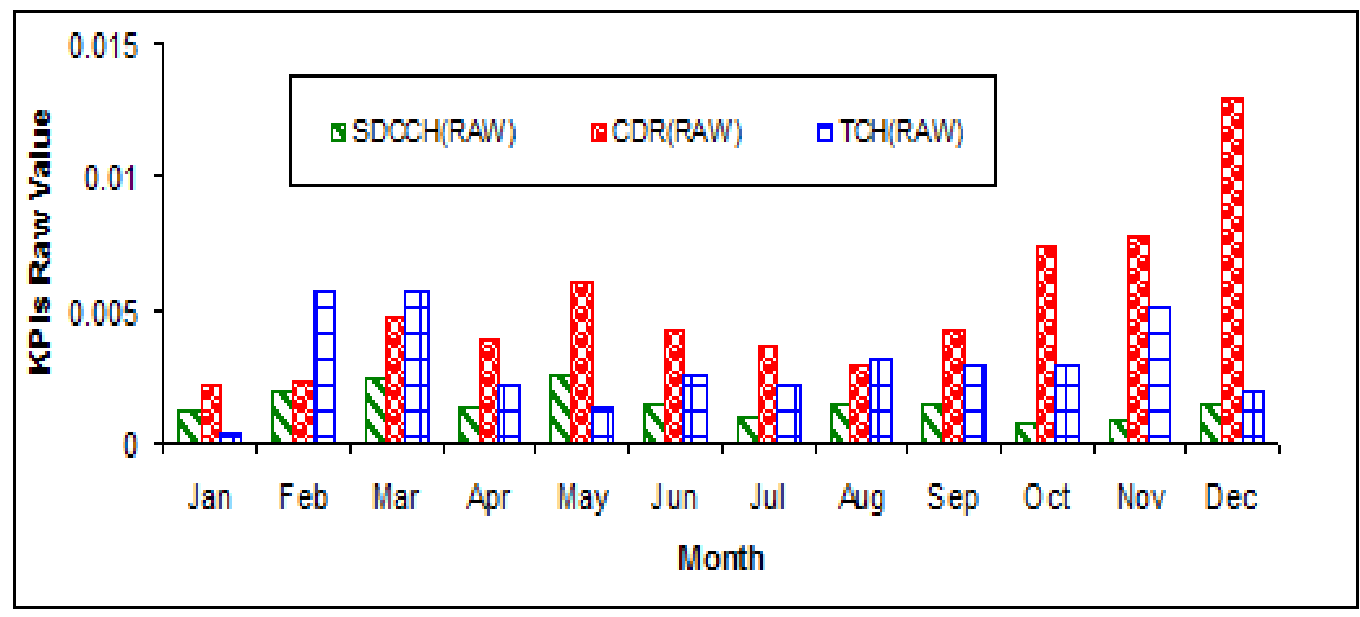

Figure 2. Summarized SDCCH, CDR and TCH KPIs data collected. 


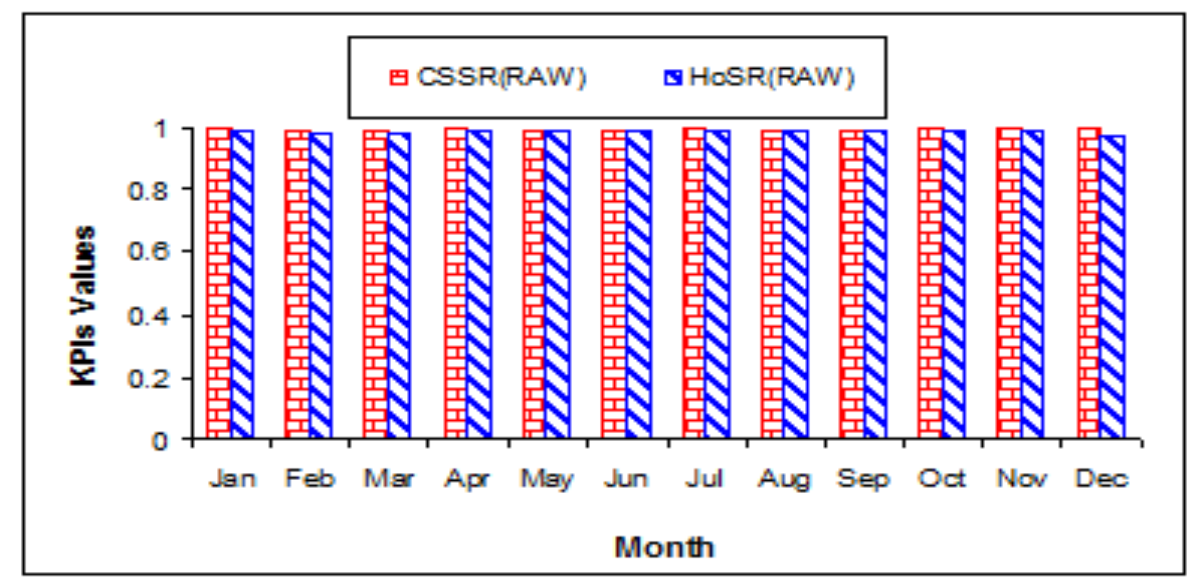

Figure 3. Summarized CSSR and HoSR KPIs data collected.

\subsection{Model development}

In modeling the proposed GSM QoS prediction model for this study, three assumptions were made. The first assumption was based on the finding in [17] that SDCCH Cong. Rate and TCH Cong. Rate are essential in service accessibility, thus a coefficient of " 1 " was assigned to the two KPIs. On the other hand, a coefficient of " 0.3333 " each was assigned to each of the remaining three KPIs based on the finding in [17] that they are only responsible for service retainability. Thus, the modeled equation for the desired QoS prediction system is expressed as;

$$
Q=\frac{S(S+0.3333 C+0.3333 D+0.3333 H+T) T}{3} \times 100 \%
$$

where $Q$ is QoS, $S$ is SDCCH Cong. Rate, $T$ is TCH Cong. Rate and $D$ is HoSR. The third assumption made was the setting of ANN performance threshold value to $77.77 \%$. The desired ANN quality of service prediction model was then developed. The set parameters for the developed ANN model are presented in Table 2. The ANN was used to define a function;

$$
f: x \rightarrow y
$$
$(y)$.

which form a generalized relationship between the KPI raw traffic data, $(x)$ and obtained QoS

In training the ANN, feed-forward back-propagation was used to find a function $f \in F$ iteratively until an optimal solution was obtained using cost function $C=E\left[\left(f(x)-y^{2}\right)\right]$ for the dataset $(x, y)$ [18]. The training was done using two different training algorithms, namely LevenbergMarquardt (L-M) and Scaled Conjugate Gradient (SCG). The architecture of the developed ANN QoS prediction model using defined variables in equation (8) as input as shown in Figure 4. Similarly, the employed ANN parameters for the developed QoS Prediction model are presented in Table 2. The reason behind the choice of the used architecture and the QoS performance evaluation results when the developed QoS prediction model was evaluated are presented and discussed in the next section. 


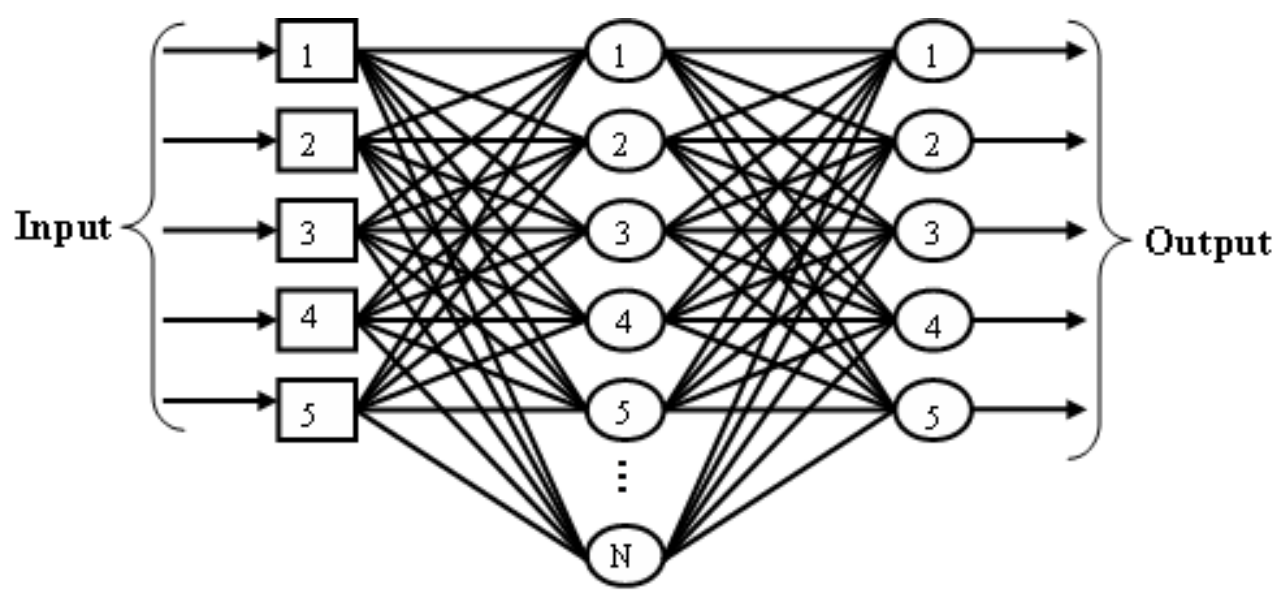

Figure 4. ANN architecture of developed QoS model.

Table 2. ANN parameters for the developed QoS prediction model

\begin{tabular}{|l|l|}
\hline \multicolumn{1}{|c|}{ Neural Network Property } & \multicolumn{1}{c|}{ Network Value } \\
\hline Network Architecture: & Feed-forward back-propagation \\
\hline Percentage of data used for Training & $70 \%$ \\
\hline Percentage of data used for Validation & $15 \%$ \\
\hline Percentage of data used for Testing & $15 \%$ \\
\hline Algorithms used for Training & (i) Levenberg-Marquardt (L-M) \\
\hline Cost function/performance function & Mean Squared Error \\
\hline Input Activation/transfer function & Sigmoid (hyperbolic tangent) \\
\hline Output layer activation function & Linear function \\
\hline Error goal & 0.001 \\
\hline Number of layers: & 2 \\
\hline Number of Neurons in Input layer & 5 \\
\hline Number of Neurons in Hidden layer & 10 \\
\hline Number of Neurons in Output layer & 5 \\
\hline Maximum Number of iterations & 1000 \\
\hline
\end{tabular}




\section{Results and discussion}

In this section, the obtained results when the developed GSM QoS prediction model was evaluated are presented and discussed. The section is divided into three subsections. In the first subsection, the inherent accuracy potential capability of the developed GSM QoS prediction model was showcased. Similarly, in the second subsection, the predicted QoS result of the developed model are presented and discussed. In addition, in the third subsection, the obtained QoS prediction results of the developed GSM QoS prediction model was compared with manually estimated QoS results by NCC. Detailed information on each subsection is presented in the following subsections.

\subsection{Inherent accuracy potential capacity result}

In showcasing the inherent accuracy prediction potential capability of the developed GSM QoS model for this study, two different matching potential capabilities of the developed QoS model were investigated. In the first instance, the matching rate of the adopted 5-10-5 (input-hidden-output) architecture for the feed-forward back-propagation ANN was first compared with other architectures. The obtained comparative performance evaluation results of the four different architectures: 5-5-5, 510-5, 5-20-5 and 5-40-5, investigated as shown in Figure 5, shows that 5-10-5 architecture is the best. The choice of 5-10-5 architecture rather than 5-20-5 architecture, with the same QoS prediction result, was based on the finding in [19] that an excessive increase in the number of hidden neurons leads to an increase in error in ANN. Also, the 5-10-5 architecture was adopted instead of 5-20-5 architecture because usage of excessive numbers of neurons in the hidden layer does cause over fitting whereby the neural networks will overestimate the complexity of the target [20,21]. Similarly, the infinitesimally small error in Figure 6 shows that there is perfect matching of the output or target result of the developed GSM QoS prediction model with the input data. This perfect matching potential of the developed QoS prediction model means that there is zero error rates between the network output and the input data set employed. Also, Figure 6 shows that the developed ANN QoS prediction model is perfectly trained.

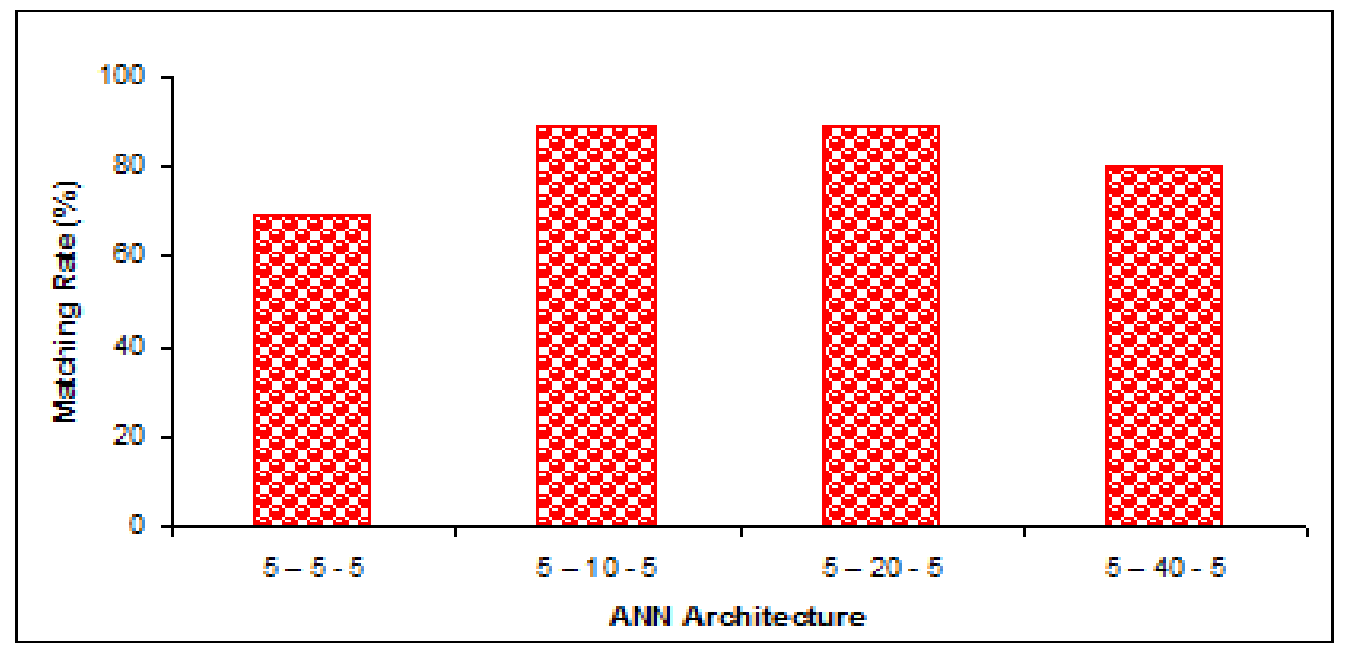

Figure 5. Percentage matching of different ANN used in developing the QoS model. 


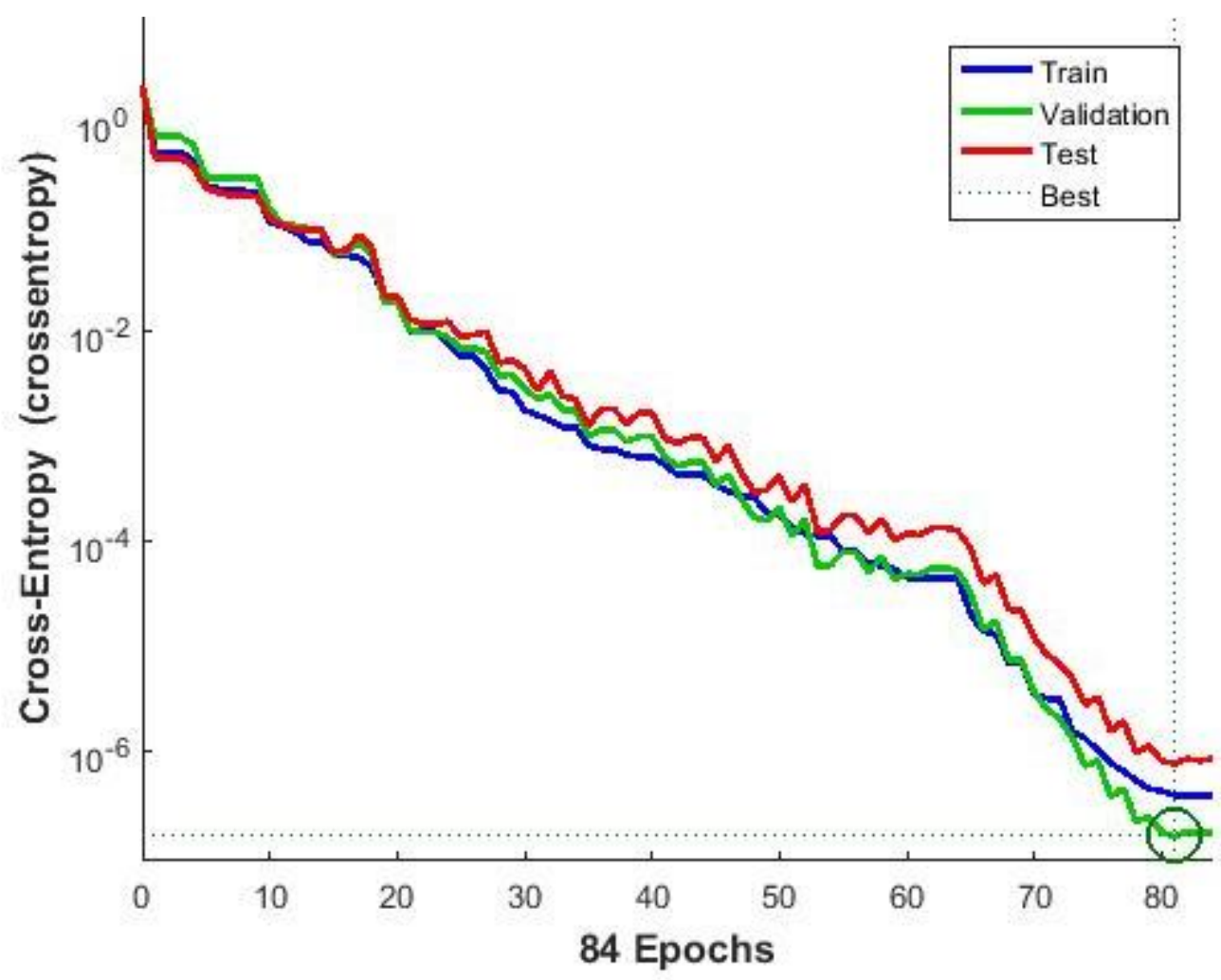

Figure 6. Matching rate potential of the developed QoS model.

\subsection{Performance evaluation result}

In assessing both the efficiency and effectiveness of the developed GSM QoS prediction model, the predicted QoS accuracy of the model was evaluated using two training algorithms, scaled conjugate gradient and Levenberg-Marquardt employed. The obtained result, as shown in Figure 7, shows that the developed QoS prediction model performed as expected. Also, the obtained performance evaluation results show that the predicted QoS using scaled conjugate gradient (SCG) training algorithm outperforms that of Levenberg-Marquardt (L-M) training algorithm. This result agrees with the finding in [22] that training algorithms have an impact on the performance of ANN system. In accordance with the third assumption stated above, the acceptable QoS threshold value was set at $77.77 \%$, which is marked in Figure 7 as a red line. Thus, from Figure 7, the network under consideration only has acceptable QoS in ten months when SCG training algorithm was used and acceptable QoS in nine months when L-M training algorithm was used out of the twelve months of the year under examination. This result shows that the network under investigation performed relatively well except in February and March when the predicted QoS was confirmed poor. 


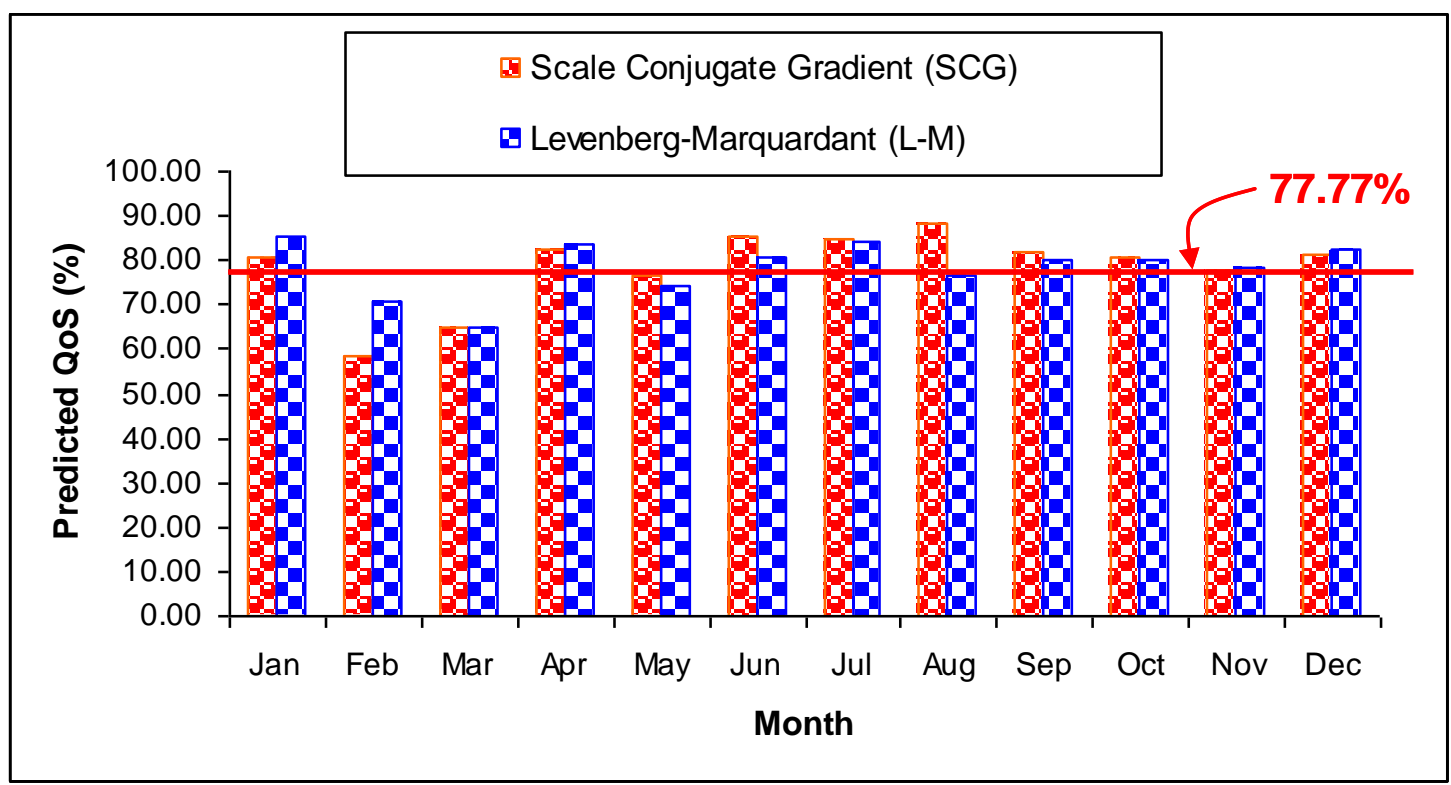

Figure 7. QoS prediction of the developed model using two different training algorithm.

\subsection{Comparative performance evaluation result}

In order to validate the accuracy of the QoS prediction result obtained from the developed QoS model for this study, the results obtained were further compared with the manually estimated result for some months in the year under examination in the NCC website. The comparative analysis was conducted using February, March, November and December comprising two confirmed poor and two confirmed good data samples in Figure 7. The asterisks on CDR and SDCCH in the months of February and March account for the reason the services in the two months were poor because the values did not meet the threshold values of $\leq 1$ and $\leq 0.2$ for CDR and SDCCH respectively. The comparative performance evaluation result, as shown in Table 3, shows that the predicted QoS results of the developed QoS model for this study performed favorably well with the manually estimated results in the NCC website for the four months. However, non-involvement of human and easy operation of the developed QoS prediction model for this study shows that the QoS prediction model for this study is not only robust but also accurate. Thus, the developed automatic QoS prediction model for this study can replace the manual method currently in use, which apart from being time consuming it is also prone to error. Also, while the developed QoS prediction model for this study automatically predicts the QoS and displays the result in numerical form without human involvement, the current approach being used by NCC requires manual calculation and interpretation by human. 
Table 3. Comparative performance of the manual method and automatic developed model

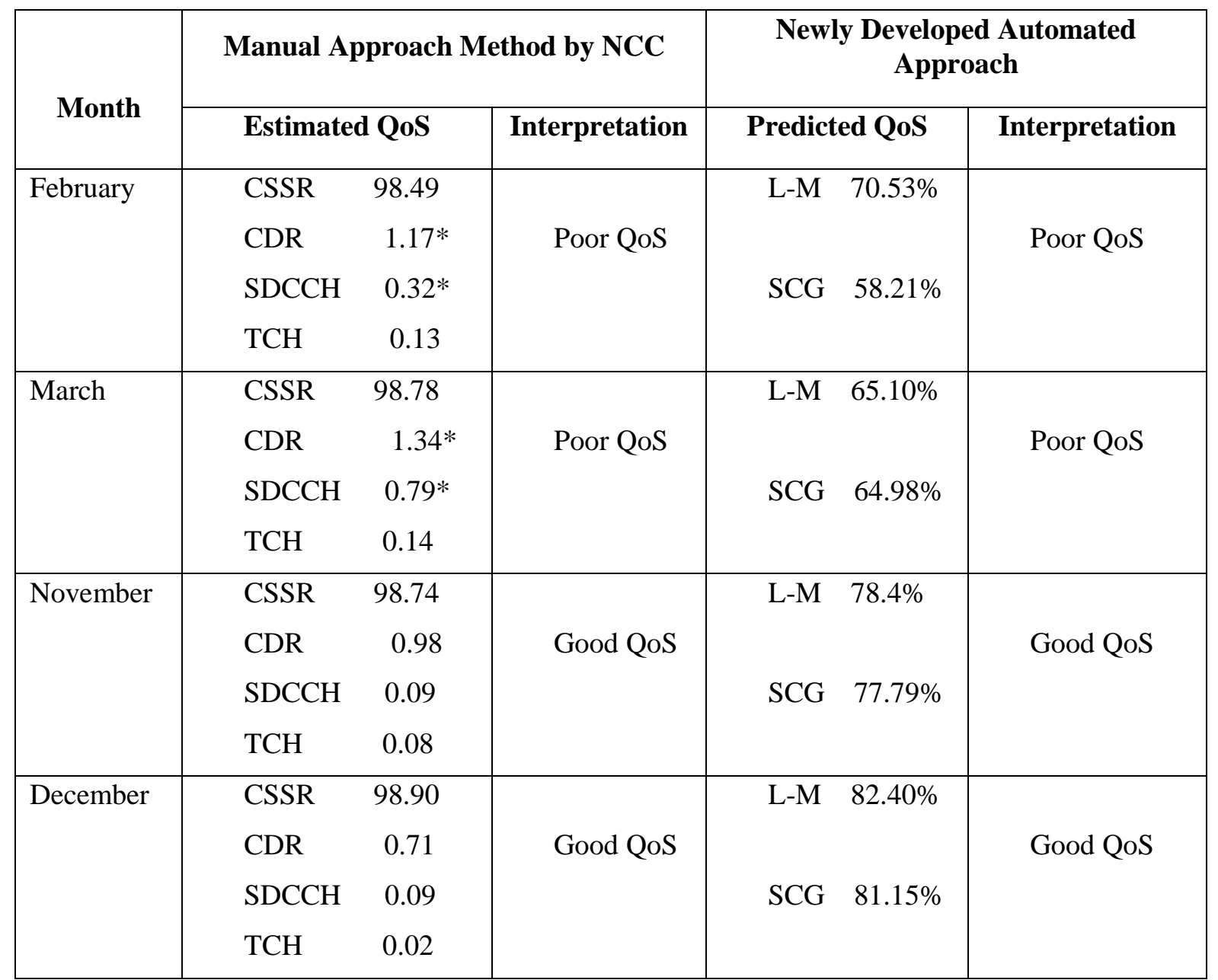

\section{Conclusion}

Currently, in Nigeria, there is no holistic model for estimating the QoS of GSM network. However, the study presented in this paper has successfully developed a model that can automatically predict the QoS of GSM network without human involvement. The developed automatic QoS prediction system was first modeled before it was developed using ANN. The results obtained when the developed QoS prediction model or system was evaluated show that the developed model performs favorably well. Also, the result of the comparative performance evaluation test carried out shows that the developed QoS prediction model for this study gives a very good representation of the QoS result obtained with the manual approach currently being used by NCC. Furthermore, the comparative performance evaluation test conducted shows that the operation of the developed QoS prediction model for this model does not only save time but is also accurate. Thus, it is suggested that the developed artificial neural network QoS prediction model for this study should be adopted by Nigerian Communications Commission and other GSM regulatory bodies in other parts of the world. 


\section{References}

[1] Popoola, J.J., Megbowon, I.O. and Adeloye, V.S.A. (2009). Performance Evaluation and Improvement on Quality of Service of Global System for Mobile Communications in Nigeria, Journal of Information Technology Impact, Vol. 9, No. 2, 91-106.

[2] Mebawondu, O.J., Dahunsi, F.M., Adewale, S.O. and Alese, B.K. (2018). Radio Access Evaluation of Cellular Network in Akure Metropolis, Nigeria, Nigerian Journal of Technology, Vol. 37, No. 3, 703-719.

[3] Bakare, A.S. and Lola, G.K. (2011). Estimating the Impacts of Global System for Mobile Communication (GSM) on Income, Employment and Transaction Cost in Nigeria, Journal of Economics and International Finance, Vol. 3, No. 1, 37-45.

[4] Okogun, O.A., Awoleye, O.M. and Siyanbola, F. (2012). Economic Value of ICT Investment in Nigeria: Is it Commensurate? International Journal of Economics and Management Sciences, Vol. 1, No. 10, 22-30.

[5] Olukotun, G., Ademola, J., Olusegun, O. and Olorunfemi, K. (2013). The Introduction of GSM Services in Anyigba Community and its Impacts on Students Expenditure Pattern, Global Journal of Management and Business Research, Vol. 13, No. 8C, 73-81.

[6] Chidozie, G., Lawal, P.O. and Ajayi, O.O. (2015). Deregulation of the Nigerian Telecommunication Sector: Interrogating the Nexus between Imperlism and Development, Academic Journal of Interdisciplinary Studies, Vol. 4, No. 1, 173-184.

[7] Nkoreh, N., Bob-Manuel, I. and Olowononi, F. (2017). The Nigerian Telecommunication Industry: Analysis of the First Fifteen Years of the Growths and Challenges in the GSM Market (2001-2016), in Proceedings of the World Congress on Engineering and Computer Science 25-27 October, San Francisco, Vol. I, 1-5.

[8] Ojo, O.J., Popoola, J.J., Oyetunji, S.A., Olasoji, Y.O. and Adu, M.R. (2019). Performance Evaluation of a Selected Cellular Mobile Operator in Ibadan Metropolis, Nigeria, Journal of Multidisciplinary Engineering Science and Technology, Vol. 6, No. 5, 10115-10124.

[9] Galadanci, G.S.M. and Abdullahi, S.B. (2018). Performance Analysis of GSM Networks in Kano Metropolis of Nigeria, American Journal of Engineering Research, Vol. 7, No. 5, 69-79.

[10] Kehinde, A.I., Lawal, S., Adunola, F.O. and Isaac, A.I. (2017). GSM Quality of Service Performance in Abuja, Nigeria, International Journal of Computer Science, Engineering and Applications, Vol. 7, No. 3/4, $29-40$.

[11] Agubor, C.K., Chukwuchekwa, N.C., Atimati, E.E., Iwuchukwu, U.C. and Ononiwu, G.C. (2016). Network Performance and Quality of Service Evaluation of GSM Providers in Nigeria: A Case Study of Lagos State, International Journal of Engineering Sciences and Research Technology, Vol. 3, No. 9, 256-263.

[12] Ozovehe, A. and Usman, A.U. (2015). Performance Analysis of GSM Networks in Minna Metropolis of Nigeria, Nigerian Journal of Technology, Vol. 34, No. 2, 359-367.

[13] Akinyemi, L.A., Makanjuola, N.T., Shoewu, O.O. and Edeko, F.O. (2014). Evaluation and Analysis 3G Network in Lagos Metropolis, Nigeria, International Journal of Electrical and Computer Engineers System, Vol. 2, No, 3, 81-87.

[14] Abayomi-Alli, A., Ezomo, P.I., Etuk, D.J., Oghogho, I. and Izilein, F. (2012). Performance Evaluation of GSM Service Providers around Igbinedion University Campuses, Advanced Materials Research, Vol. 367, 177-184.

[15] Popoola, J.J. and van Olst, R. (2011). Automatic Classification of Combined Analog and Digital Modulation Schemes using Feedforward Neural Network, in Proceedings of IEEE AFRICON, Livingstone, Zambia, 13-15 September, doi:101109/AFRICON.2011.607208

[16] Stauba, S., Karamanb, E., Kayaa, S., KarapÕnara, H. and Güvena, E. (2015). Artificial Neural Network and Agility, Procedia - Social and Behavioral Sciences, Vol. 195, 1477 - 1485.

[17] Javed, A.K. and Irfan, Z. (2017). Correlation between Network KPIs and User Experience of GSM Networks in Pakistan. Innovative Systems Design and Engineering, Vol. 8, No. 3, 1-10. 
[18] Agbolade, O.A. and Oyetunji, S.A. (2016). Voice Conversion Using Coefficient Mapping and Neural Network, in Proceedings of International Conference for Students on Applied Engineering, 20-21 October, Newcastle Upon Tyne, UK, 479-483.

[19] Shafi, I., Ahmed, J., Jamil, A., Shah, S.I. and Kashif, F.M. (2006). Impact of Varying Neurons and Hidden Layers in Neural Network Architecture for a Time Frequency Application, in Proceedings of IEEE International Multitopic Conference, Islamabad, Pakistan, 188-193.

[20] Sheela, K.G. and Deepa, S.N. (2013). Review on Method to Fix Number of Hidden Neurons in Neural Networks, Mathematical Problems in Engineering, Vol. 2013, 1-11.

[21] Jinchuan, K. and Xinzhe, L. (2008). Empirical Analysis of Optimal Hidden Neurons in Neural Network Modeling for Stock Prediction, in Proceedings of the Pacific-Asia Workshop on Computational Intelligence and Industrial Application, Vol. 2, 828-832.

[22] Popoola, J.J. and Van Olst, R. (2013). Effect of Training Algorithms on Performance of a Developed Automatic Modulation Classification Using Artificial Neural Network, in Proceedings of IEEE AFRICON, Paradise Island, Mauritius, 9-12 September, doi:10.1109/AFRICON.2013.6757676. 